\title{
Stem extract of Albizia richardiana exhibits potent antioxidant, cytotoxic, antimicrobial, anti-inflammatory and thrombolytic effects through in vitro approach
}

Mohammad Nazmul Islam ${ }^{1,2^{*}}$ (D), Homyra Tasnim³ ${ }^{3}$ Laiba Arshad ${ }^{4}$, Md. Areeful Haque ${ }^{1,5}$, Syed Mohammed Tareq ${ }^{1}$, A. T. M. Mostafa Kamal' ${ }^{1}$, Md. Masudur Rahman'', A S. M. Ali Reza', Kazi Ashfak Ahmed Chowdhury ${ }^{1}$ and Abu Montakim Tareq ${ }^{1}$

\begin{abstract}
Background: Albizia richardiana belongs Fabaceae family which different parts like fruits, flowers, barks, and roots are used medicinally. The study reports the in vitro anti-inflammatory, thrombolytic, cytotoxicity and antimicrobial activity of methanolic extract of $A$. richardiana stem and its different fractions.

Method: The methanolic extract of $A$. richardiana stem (MEAR) extracted with n-hexane (HXFAR), carbon tetrachloride (CTFAR), chloroform (CFAR), and aqueous (AQFAR) and subjected for DPPH scavenging activity and total phenol content (TPC). The cytotoxic activity evaluated by brine shrimp lethality bioassay, while the disk diffusion method used for the antimicrobial study. The anti-inflammatory and thrombolytic activities of the extracts evaluated by the hypotonic solution induced hemolysis, heat-induced hemolysis and human blood clot lysis, respectively.
\end{abstract}

Results: All the extracts exhibited excellent antioxidant activity in the DPPH scavenging assay and maximum total phenol content observed by HXFAR. Secondly, the extract showed a moderate $\mathrm{LC}_{50}$ value in brine shrimp lethality bioassay, where the CTFAR extract exhibited potential antimicrobial activities against sixteen different microorganisms. In anti-inflammatory, all the extract exhibited a significant $(P<0.0001)$ protection against lysis of human erythrocyte membrane induced by heat and hypotonic solution, as compared to the standard acetyl salicylic acid. An extremely significant $(P<0.0001)$ clot lysis was found in MEAR $(16.66 \%)$ while the standard drug streptokinase (70.94\%).

Conclusion: All the fractions revealed the significant free radical scavenging activity. Moreover, CTFAR showed wide spectrum of antimicrobial activity. Thus, the results of the present study provided scientific evidence for the use of Albizia richardiana as traditional medicine.

Keywords: Albizia richardiana, Anti-inflammatory, Antioxidant, Antimicrobial

\footnotetext{
*Correspondence: sayeadiiuc@gmail.com

'Department of Pharmacy, International Islamic University Chittagong,

Chittagong-4318, Bangladesh

2Department of Pharmacy, State University of Bangladesh, Dhaka-1205,

Bangladesh

Full list of author information is available at the end of the article
}

\section{Springer Open}

(c) The Author(s). 2020 Open Access This article is licensed under a Creative Commons Attribution 4.0 International License, which permits use, sharing, adaptation, distribution and reproduction in any medium or format, as long as you give appropriate credit to the original author(s) and the source, provide a link to the Creative Commons licence, and indicate if changes were made. The images or other third party material in this article are included in the article's Creative Commons licence, unless indicated otherwise in a credit line to the material. If material is not included in the article's Creative Commons licence and your intended use is not permitted by statutory regulation or exceeds the permitted use, you will need to obtain permission directly from the copyright holder. To view a copy of this licence, visit http://creativecommons.org/licenses/by/4.0/. 


\section{Background}

Plant is a resourceful preference to produce drug which is important to keep the world healthy [1]. Plants are used to cure, prevent the diseases whereas $75 \%$ of world population depends on herbal drugs for their primary healthcare [2, 3]. Albizia richardiana King \& Prain belongs Fabaceae family which is found in Asia, Africa and Australia [4]. Different parts like fruits, flowers, barks, roots etc. are used medicinally [5]. A. richardiana are used in treating depression, appetite, increase blood circulation, tightness in chest, eye problems, blurred vision and pain in back [6]. This plant reported to have several secondary metabolites in bark such as carbohydrates, saponins, glucosides, glycosides and alkaloids. It was also reported to have significant antioxidant activity while lethal concentration $\left(\mathrm{LC}_{50}\right)$ was extremely toxic in bark extract. The hypoglycemic and antimicrobial activity was also evaluated [7].

Secondary metabolites of plants are not necessary for survival of plant but essential for the development of plant, reproduction, growth, protection etc. [8]. Phenolic are highly distributed in plant species which are useful in physical and biological stress [9, 10]. Phenolic compounds effective for human health for their various biological effects such as antioxidant, anti-microbial, anticancer, and anti-allergic effects [11].

Reactive oxygen species (ROS) incorporates both oxygen and non-radicals that are generated during usual metabolic processes [12]. Excessive production of ROS may lead to oxidative chain reactions which imbalance the antioxidants in body. This imbalance may affect in health conditions and molecular function [13-15]. The imbalance may cause several diseases such as neurodegenerative diseases, cancer, allergies, cardiac problem [16]. Antioxidants (present in human body or obtained by food or plants) can suppress the oxidative responses or free radicals, in this manner restricting the oxidative damage [17]. So, intake of dietary of plant derived antioxidants may reduce or prevent the oxidative stress and intake of additional medicine [18].

Our present research study design to investigate the in vitro anti-inflammatory, thrombolytic, cytotoxicity and antimicrobial activity of methanolic extract of $A$. richardiana and its different fractions. To our knowledge, there are no such study was design or published by using the stem of A.richardiana.

\section{Materials and methods}

\section{Sample collection and preparation}

A. richardiana stem was collected from hilly area of Chittagong, Bangladesh which was identified by the Professor Dr. Shaikh Bokhtear Uddin, Department of Botany, University of Chittagong, Bangladesh. Stem was cut into small pieces and dried in sun-light for couple of days. For better grinding the sun-dried stem was also applied in oven. After that the dried stem was crushed with a high capacity grinding machine and the ultimate product was coarse powder of A.richardiana ( $0.5 \mathrm{~kg})$.

\section{Drugs and chemicals}

Folin-Ciocalteu reagent (10 fold diluted), (Merck, St. Louis, MO, USA), Methanol, Chloroform, Carbon tetra chloride (Merck Darmstadt, Germany), Brine shrimp egg (SK brand, Thailand), vincristine sulphate (Sigma- Aldrich Co). The Human RBCs were collected from a 70 $\mathrm{kg}$ diseased free male of fair complexion. The collected RBCs were kept in a test tube with an anticoagulant EDTA under standard conditions of temperature $23 \pm$ $2{ }^{\circ} \mathrm{C}$ and relative humidity $55 \pm 10 \%$. Lyophilized Alteplase (Streptokinase) vial of 15, 00,000 I.U. was purchased from Beacon Pharmaceuticals Ltd. All other chemicals are in analytical grade.

\section{Test microorganisms}

Gram positive bacteria (Bacillus cereus, Bacillus megaterium, Bacillus subtillis, Sarcina lute, and Staphylococcus aureus), gram negative bacteria (Escherichia coli, Salmonella paratyphi, Salmonella typhi, Shigella boydii, Shigella dysenteriae, Pseudomonas aeruginosa, Vibrio mimicus, Vibrio parahemolyticus) and fungal strains (Aspergillus niger, Candida albicans, Saccharomyces cerevisiae) were used for antimicrobial assay. The microorganisms were provided by State University of Bangladesh.

\section{Experimental design Extraction of plant material}

The coerced powder of stem was macerated in 1.5 Liter of methanol in an amber glass bottle. The bottle was kept in a dry place with occasional shaking and stirring. After 14 days, the mixture was filtered through cotton and Whitman filter paper \#1 respectively. The obtained volume of filtrate was reduced by evaporation at atmospheric temperature until $70 \%$ solvent was evaporated. Finally, a crude semi-solid methanolic extract of $A$. richardiana obtained (5 g).

\section{Solvent- solvent partitioning}

The crude extract is fractionated using the solventsolvent partitioning protocol, designed by Kupchan et al. and modified by Van Wagenen et al. [19]. All the fractioned (HXFAR, CTFAR, CFAR, and AFAR) were subjected to evaporate for drying to be used further analysis. 


\section{Antioxidant activity DPPH scavenging assay}

To evaluate anti-oxidant potential of the plant extract, DPPH assay was used employing the method of BrandWilliams et al., 1995 [20]. Therefore, each test sample containing $2 \mathrm{~mL}$ of serially diluted different concentrations $(500 \mu \mathrm{g} / \mathrm{mL}$ to $0.977 \mu \mathrm{g} / \mathrm{mL})$ was mixed with $3 \mathrm{~mL}$ of a DPPH methanol solution $(20 \mu \mathrm{g} / \mathrm{mL})$. Following a 30 min reaction period $\left(25^{\circ} \mathrm{C}\right)$ a dark place, the absorbance was measured at $517 \mathrm{~nm}$ by UV spectrophotometer. Finally, $\mathrm{IC}_{50}$ values were calculated from the graph plotting concentration of the sample against percentage inhibition of free radicals. As positive control, ascorbic acid and butylated hydroxyl toluene were used.

\section{Total phenolic component analysis}

The total phenolic content of $A$. richardiana stem was assessed by using the previously described method of Skerget et al. (2005) [21]. Folin-Ciocalteu reagent used as an oxidizing agent whereas gallic acid was used as reference. The $A$. richardiana stem extract $(2 \mathrm{mg})$ was dissolved in the distilled water to obtain a sample concentration of $2 \mathrm{mg} / \mathrm{mL}$. Afterwards, a mixture consisting of $0.5 \mathrm{ml}$ extract solution (conc. $2 \mathrm{mg} / \mathrm{ml}$ ), $2.5 \mathrm{~mL}$ Folin-Ciocalteu reagent (diluted ten times with water) and $2 \mathrm{ml} \mathrm{Na} \mathrm{CO}_{3}(7.5 \% \mathrm{w} / \mathrm{v})$ solution was prepared and incubated for $20 \mathrm{~min}$ at room temperature. Finally, the absorbance of the mixture was determined with UVspectrophotometer at $760 \mathrm{~nm}$ and the total phenolic content of the sample was calculated from absorbance. The standard curve was also prepared from gallic acid solution using different concentrations. The unit of phenolic content is expressed as mg of GAE (gallic acid equivalent)/gm of the extract.

\section{Cytotoxic activity assay}

Brine shrimp lethality bioassay was performed to assess possible cytotoxic activity (Meyer et al., 1982) [22]. Brine shrimp eggs collected from pet shops were hatched in simulated seawater (prepared from $38 \mathrm{~g}$ sea salt dissolving in one liter of distilled water) with constant oxygen supply till they mature to nauplii. The test sample was taken in a vial and dissolved in $200 \mu \mathrm{L}$ pure dimethyl sulfoxide (DMSO), from which each time $100 \mu \mathrm{L}$ solution was transferred to a test tube containing $5 \mathrm{~mL}$ simulated sea water and 10 shrimp nauplii. Test samples of different concentrations were prepared applying the sequential dilution method. For validation of the test method and ensuring that the obtained results only reflect the activity of the test agent and nullify effects of other possible factors, positive and negative control groups were used. Vincristine sulfate was added as a positive control to DMSO to obtain different concentrations through serial dilutions, which were later added to the pre-marked test tube containing $5 \mathrm{~mL}$, simulated sea water and 10 shrimp nauplii to get a positive control group. Next, a comparative analysis is done between the result of test agent and positive control group. For negative control, $100 \mu \mathrm{L}$ DMSO is added to each of the premarked simulated sea water $(5 \mathrm{~mL})$, and shrimp nauplii ( $n=10)$ filled test tubes. Rapid mortality of the brine shrimps indicates the test is invalid as the nauplii died due to reason other than the cytotoxicity of the compounds. After $24 \mathrm{~h}$, visual inspection with a magnifying glass was done to count the survivors and concentration-mortality data were analyzed statistically using IBM-PC program. Median lethal concentration $\left(\mathrm{LC}_{50}\right)$ was used to express the effectiveness or concentration-mortality relationship of plant product. It represents the concentration of a chemical that produces death in half of the test subjects after a specific exposure period.

\section{Antimicrobial assay}

In this study, the antimicrobial property of crude extracts as well as fractions of $A$. richardiana was tested using the disc diffusion method [23, 24]. The bacterial and fungal strains used for the experiment were obtained from the State University of Bangladesh. Standard Ciprofloxacin $(30 \mu \mathrm{g} /$ disc $)$ and blank discs were used as positive and negative control respectively. Nutrient agar medium was used to assess the sensitivity of the organisms to the test materials. On the previously marked zones of the agar plates pre-inoculated with test bacteria and fungi; the sample discs, the standard antibiotic discs and the control discs were placed gently. The plates were then incubated at $37^{\circ} \mathrm{C}$ for $24 \mathrm{~h}$. After incubation, the clear zone of inhibition surrounding the discs was measured which determines the antimicrobial potency of the test agents.

\section{Anti-inflammatory activity}

To evaluate anti-inflammatory activity, hypotonic solution induced hemolysis and heat-induced hemolysis techniques were adopted.

\section{Hypotonic solution induced hemolysis}

Hypotonic solution induced hemolysis was evaluated by using the previously described method [25]. The experiment included test sample consisting of stock erythrocyte (RBC) suspension $(0.50 \mathrm{~mL})$ with $5 \mathrm{~mL}$ of hypotonic solution $(50 \mathrm{mM} \mathrm{NaCl})$ in $10 \mathrm{mM}$ sodium phosphate buffer saline ( $\mathrm{pH} 7.4)$ containing either different methanol extracts $(2 \mathrm{mg} / \mathrm{mL})$ or Acetylsalicylic acid $(0.10 \mathrm{mg}$ / $\mathrm{mL}$ ). The acetylsalicylic acid was used as a reference standard. All these mixtures were subjected to incubation for $10 \mathrm{~min}$ at room temperature and then centrifuged for $10 \mathrm{~min}$ at $3000 \mathrm{~g}$, and the absorbance (O.D.) of the supernatant was determined at $540 \mathrm{~nm}$ using 
Shimadzu UV spectrometer. The percentage inhibition of either hemolysis or membrane stabilization was calculated applying the following equation:

\%Inhibition of hemolysis $=100 \times\left\{\left(\mathrm{OD}_{1}-\mathrm{OD}_{2}\right) / \mathrm{OD}_{1}\right\}$

Where,

$\mathrm{OD}_{1}=$ Optical density of hypotonic-buffered saline solution alone (control) and

$\mathrm{OD}_{2}=$ Optical density of test sample in hypotonic solution.

\section{Heat-induced hemolysis}

Heat-induced hemolysis was evaluated by using the standard protocol [25]. Aliquots $(5 \mathrm{~mL})$ of the isotonic buffer containing $1 \mathrm{mg} / \mathrm{mL}$ of different extractives were taken into two duplicate sets of centrifuge tubes. The vehicle, in the same amount, was added to another tube as control and erythrocyte suspension $(30 \mu \mathrm{L})$ was added to each tube and mixed with gentle inversion. One pair of the tubes was incubated at $54^{\circ} \mathrm{C}$ for $20 \mathrm{~min}$ in a water bath, while the other pair was maintained at $0-5^{\circ} \mathrm{C}$ in an ice bath. The reaction mixture was centrifuged for 3 min at $1300 \mathrm{~g}$, and the absorbance of the supernatant was measured at $540 \mathrm{~nm}$. The percentage inhibition of hemolysis was calculated according to the equation:

\%Inhibition of hemolysis $=100 \times\left[1-\left(\mathrm{OD}_{2}-\mathrm{OD}_{1} / \mathrm{OD}_{3}-\mathrm{OD}_{1}\right)\right]$

Where,

$\mathrm{OD}_{1}=$ test sample unheated, $\mathrm{OD}_{2}=$ test sample heated and $\mathrm{OD}_{3}=$ control sample heated

\section{Thrombolytic activity assay}

To investigate the thrombolytic activity of methanol extracts and different fractions of $A$. richardiana, $10 \mathrm{mg}$ of methanol extracts along with its different fractions were added to different vials each containing $1 \mathrm{~mL}$ of distilled water. Aliquots $(5 \mathrm{~mL})$ of venous blood were drawn from healthy volunteers (without a history of use of oral contraceptive or anticoagulant therapy) and distributed in 10 different pre-weighted sterile vials ( $1 \mathrm{~mL} /$ tube). The vials were then incubated at $37{ }^{\circ} \mathrm{C}$ for $45 \mathrm{~min}$. In order to determine the clot weight, the vials were again weighed after clot formation. A $100 \mu \mathrm{L}$ aqueous solution of different fractioned along with the crude extracts was added separately to each vial containing pre-weighted clot. Also, $100 \mu \mathrm{L}$ of streptokinase (SK) and $100 \mu \mathrm{L}$ of distilled water were separately added to the control vial as a positive and negative control respectively. All the vials were then subjected to incubation at $37^{\circ} \mathrm{C}$ for 90 min and observed for clot lysis. Once the incubation was over, the released fluid was removed, and vials were weighed again to express the percentage of clot lysis from the difference in weight measured before and after clot lysis.

$\%$ Clot lysis $=($ weight of clot after remove of fluid $/$ clot weight $) \times 100$

\section{Statistical analysis}

Values are represented in Mean $\pm \operatorname{SEM}(n=3) . P<0.05$ is considered as statistically significant in comparison to control group where One-way ANOVA was followed by GraphPad Prism (Ver 7).

\section{Results and discussion DPPH scavenging activity}

The antioxidant activity by DPPH assay and total phenol content (TPC) was summarized in Tables 1 and 2, respectively. The $A$. richardiana showed a significant antioxidant activity by CFAR $(5.49 \mu \mathrm{g} / \mathrm{mL})$, HXFAR $(11.26 \mu \mathrm{g} /$ $\mathrm{mL})$ and CTFAR $(12.98 \mu \mathrm{g} / \mathrm{mL})$ in comparison to standard ascorbic acid $(14.14 \mu \mathrm{g} / \mathrm{mL})$, followed by other two fractioned AQFAR $(81.99 \mu \mathrm{g} / \mathrm{mL})$ and MEAR $(155.32 \mu \mathrm{g} / \mathrm{mL})$.

The total phenol content in A. richardiana was evaluated by the Folin-Ciocalteu's reagent which expressed as $\mathrm{GAE} / \mathrm{g}$ of dried extract. The regression equation found from standard gallic acid was: $Y=0.0162 x+0.0215 ; R^{2}=$ 0.9985 . The highest total phenolic content was found in n-hexane fraction of A. richardiana $54.05 \mathrm{mg}$ GAE/g. The order of TPC antioxidant activity as followed: HXFAR > AQFAR > CTFAR > MEAR >CFAR.

Oxidative damage resulting an imbalance between the antioxidant defense system and free radical (FS) generation [26] which lead to several damage of protein, nucleic acid and lipids [27]. Oxidative stress initiated by tissues infection or injury by physical injury, hypertoxia, any chemical (toxin) and excessive exercise which produce increase amount of xanthine oxidase, disruption in oxidative phosphorylation and excess reactive oxygen species (ROS). Excess production of ROS, cause several complications such as cardiac disease, diabetes, aging, Parkinson's disease [28]. In biological system, phenolic and flavonoid like content are important for antioxidant

Table $1 \mathrm{IC}_{50}$ values of methanolic extract of Albizia richardiana and standard reference ascorbic acid with regression equation

\begin{tabular}{lll}
\hline Sample & $I_{\mathbf{5 0}}$ & Regression equation \\
\hline Ascorbic acid & 14.14 & $y=0.1002 x+48.583 ; R^{2}=0.953$ \\
MEAR & 155.32 & $y=0.1027 x+34.049 ; R^{2}=0.328$ \\
HXFAR & 11.26 & $y=0.0752 x+49.153 ; R^{2}=0.7079$ \\
CTFAR & 12.95 & $y=0.104 x+48.653 ; R^{2}=0.9016$ \\
CFAR & 5.49 & $y=0.1087 x+49.403 ; R^{2}=0.8057$ \\
AQFAR & 81.99 & $y=0.1072 x+41.211 ; R^{2}=0.9129$
\end{tabular}

MEAR methanolic extract of Albizia richardiana, HXFAR n-hexane fraction of Albizia richardiana, CTFAR carbon tetrachloride fraction of Albizia richardiana, CFAR chloroform fraction of Albizia richardiana and AQFAR aqueous fraction of Albizia richardiana 
Table 2 Effect of different extractives of stem of Albizia richardiana on Total phenol content

\begin{tabular}{lll}
\hline Sample & Total phenol content (mg GAE/g extract) & Regression equation \\
\hline MEAR & 11.03 & $Y=0.0162 x+0.0215 ; R^{2}=0.9985$ \\
HXFAR & 54.05 & \\
CTFAR & 12.01 & \\
CFAR & 2.02 & \\
AQFAR & 20.09 &
\end{tabular}

MEAR methanolic extract of Albizia richardiana, HXFAR $\mathrm{n}$-hexane fraction of Albizia richardiana, CTFAR carbon tetrachloride fraction of Albizia richardiana, CFAR chloroform fraction of Albizia richardiana and AQFAR aqueous fraction of Albizia richardiana

activity which is reported by scientists [29, 30]. The phenolic compound is important in defense of plants and signaling pathway. The mechanism of inhibition by phenol compounds in free radical is, by transferring a $\mathrm{H}$-atom form the hydroxyl group $(\mathrm{OH})$. Phenolic compounds are responsible in reducing the neurodegenerative disease [31]. In our experiment, the plant extract and it's fractioned of $A$. richardiana found enriched in antioxidant activity.

\section{Cytotoxic activity}

Brine shrimp lethality assay reveals the $\mathrm{LC}_{50}$ values of the test fractions range between $106.10-194.85 \mu \mathrm{g} / \mathrm{mL}$ in light condition and $124.83-182.16 \mu \mathrm{g} / \mathrm{mL}$ in dark condition whereas standard Vincristine sulfate $0.27 \mu \mathrm{g} / \mathrm{mL}$ (Table 3). Among all extract of stem of $A$. richardiana, the lowest brine shrimp lethality was demonstrated by CTFAR $106.10 \mu \mathrm{g} / \mathrm{mL}$ followed by HXFAR $194.78 \mu \mathrm{g} /$ $\mathrm{mL}$, MEAR $188.59 \mu \mathrm{g} / \mathrm{mL}$, AQFAR $181.95 \mu \mathrm{g} / \mathrm{Ml}$ and CFAR $156.98 \mu \mathrm{g} / \mathrm{mL}$ under light condition, and CTFAR $124.83 \mu \mathrm{g} / \mathrm{mL}$ followed by MEAR $195.05 \mu \mathrm{g} / \mathrm{mL}$, AQFAR $182.16 \mu \mathrm{g} / \mathrm{Ml}$, CFAR $156.62 \mu \mathrm{g} / \mathrm{mL}$ and HXFAR

Table $3 L_{50}$ values of methanolic extract of Albizia richardiana at light and dark condition with regression equation as well as standard vincristine sulfate

\begin{tabular}{llll}
\hline Condition & Sample & $L_{\mathbf{5 0}}$ & Regression equation \\
\hline Light condition & MEAR & 188.59 & $y=0.1967 x+12.905 ; R^{2}=0.8712$ \\
& HXFAR & 194.78 & $y=0.1576 x+19.303 ; R^{2}=0.7232$ \\
& CTFAR & 106.10 & $y=0.192 x+29.628 ; R^{2}=0.8679$ \\
& CFAR & 156.98 & $y=0.109 x+32.889 ; R^{2}=0.728$ \\
& AQFAR & 181.95 & $y=0.1215 x+27.893 ; R^{2}=0.4947$ \\
Dark condition & MEAR & 195.05 & $y=0.1702 x+16.801 ; R^{2}=0.6941$ \\
& HXFAR & 141.34 & $y=0.1797 x+24.601 ; R^{2}=0.7793$ \\
& CTFAR & 124.83 & $y=0.1982 x+25.259 ; R^{2}=0.9071$ \\
& CFAR & 156.62 & $y=0.1316 x+29.388 ; R^{2}=0.7868$ \\
Standard & AQFAR & 182.16 & $y=0.1211 x+27.94 ; R^{2}=0.5776$ \\
& VS & 0.27 & $y=4.9808 x+48.657 ; R^{2}=0.5778$
\end{tabular}

VS Vincristine sulfate, MEAR methanolic extract of Albizia richardiana, HXFAR $\mathrm{n}$ hexane fraction of Albizia richardiana, CTFAR carbon tetrachloride fraction of Albizia richardiana, CFAR chloroform fraction of Albizia richardiana and AQFAR aqueous fraction of Albizia richardiana
141.34 $\mu \mathrm{g} / \mathrm{mL}$ under dark condition respectively. Mostly, the higher the lethal concentration the lower will be the $\mathrm{LC}_{50}$ and vice versa. The value of $\mathrm{LC}_{50}$ over $1000 \mu \mathrm{g} / \mathrm{ml}$ is considered to be non-toxic, ranging from 500 to $1000 \mu \mathrm{g} / \mathrm{ml}$ is weakly toxic, moderately toxic for 100 $500 \mu \mathrm{g} / \mathrm{ml}$ while less than $100 \mu \mathrm{g} / \mathrm{ml}$ is considered as highly toxic [32]. Here, all extract are shown a moderate toxicity, Hence, the extract required cation at treatment while overdosing.

\section{Anti-microbial activity}

In anti-microbial screening performed at the dose of $400 \mu \mathrm{g} /$ disc by disc diffusion method, the carbon tetrachloride soluble fraction (CTFAR) exhibited the highest inhibition against microbial growth with a zone of inhibition ranged from 7 to $23 \mathrm{~mm}$. The HXFAR and CFAR also exhibited minimum inhibition against microbial growth while AFAR did not exhibit any. The results indicate that CTFAR possesses better antimicrobial activity against gram positive, gram negative as well as fungi and can be studied further to explore potent anti-microbial agent (Table 4).

The antimicrobial potential of plants was studied by zone of inhibition of different microorganisms of gram positive, gram negative and fungi. Different fraction of A. richardiana showed their potential activity. Except CTFAR, none of the fraction exhibits a positive inhibition of growth of microorganisms. From the result, the antimicrobial activity can be mentioned that methanol, n-hexane, carbon tetra chloride extract of $A$. richardiana might be a broad spectrum antibacterial agent against the tested organisms.

\section{Anti-inflammatory activity}

The anti-inflammatory activity was presented in Figs. 1 and 2. The different methanol extract and fractions of $A$. richardiana stem at concentration $2.0 \mathrm{mg} / \mathrm{mL}$ significantly $(P<0.0001)$ protected the lysis of human erythrocyte membrane induced by heat and hypotonic solution, as compared to the standard acetylsalicylic acid $(0.10$ $\mathrm{mg} / \mathrm{mL}$ ). The erythrocyte membrane resembles to lysosomal membrane and as such, the effect of drugs on the stabilization of erythrocyte could be extrapolated 
Table 4 Antimicrobial activity of test samples of Albizia richardiana

\begin{tabular}{|c|c|c|c|c|c|c|c|}
\hline \multirow[t]{3}{*}{ Strain } & \multirow[t]{3}{*}{ Test microorganism } & \multicolumn{6}{|c|}{ Diameter of Zone of inhibition (mm) } \\
\hline & & \multicolumn{5}{|c|}{ Concentration ( $\mu \mathrm{g} / \mathrm{disc})$} & \multirow{2}{*}{$\begin{array}{l}\text { Ciprofloxacillin } \\
\text { (30 } \mu \mathrm{g} / \text { disc) }\end{array}$} \\
\hline & & MEAR & HXFAR & CTFAR & CFAR & AFAR & \\
\hline & Bacillus cereus & - & - & 22 & - & - & 44 \\
\hline & Bacillus megaterium & - & - & 12 & - & - & 37 \\
\hline \multirow[t]{6}{*}{ GPB } & Staphylococcus aureus & 16 & 9 & 14 & - & - & 38 \\
\hline & Sarcina lutea & - & - & 21 & - & - & 45 \\
\hline & Bacillus subtilis & 11 & - & 16 & - & - & 41 \\
\hline & Escherichia coli & 7 & - & 16 & - & - & 46 \\
\hline & Pseudomonas aeruginosa & - & - & - & - & - & 45 \\
\hline & Salmonella partyphi & - & - & 12 & - & - & 40 \\
\hline \multirow[t]{6}{*}{ GNB } & Salmonella typhi & 8 & - & 12 & - & - & 46 \\
\hline & Shigella boydii & 8 & 10 & 16 & - & - & 42 \\
\hline & Shigella dysenteriae & - & 9 & 12 & - & - & 46 \\
\hline & Vibrio mimicus & - & 8 & 12 & - & - & 44 \\
\hline & Vibrio parahemolyticus & 11 & 13 & 20 & - & - & 45 \\
\hline & Candida albicans & 7 & 9 & 18 & - & - & 47 \\
\hline \multirow[t]{2}{*}{ Fungi } & Aspergillus niger & 12 & 13 & 23 & - & - & 51 \\
\hline & Saccharomyces cerevisiae & 10 & 12 & 15 & - & - & 46 \\
\hline
\end{tabular}

GPB Gram positive bacteria, GNB Gram negative bacteria. MEAR methanolic extract of Albizia richardiana, HXFAR $\mathrm{n}$-hexane fraction of Albizia richardiana, CTFAR carbon tetrachloride fraction of Albizia richardiana, CFAR chloroform fraction of Albizia richardiana and AQFAR aqueous fraction of Albizia richardiana

to the stabilization of lysosomal membrane [33]. In both the hypotonic solution and heat-induced condition the highest membrane stabilizing activity was demonstrated by the CTFAR $(62.29 \pm 0.41 \%$ and $85.71 \pm 0.71 \%$, respectively). Significant membrane stabilizing activity was also exhibited in other extract in both conditions. The results clearly indicated that the extract of the stem of $A$. richardiana were highly effective in the membrane stabilizing activity as to prevent the lysis of erythrocyte induced by hypotonic solution and heat. Previous studies have reported that flavonoids exert profound stabilizing effects on lysosomes both in vitro and in vivo experimental animals while tannin and saponins have the ability to bind cation and other biomolecules, and are able to stabilize erythrocyte membrane [34, 35].

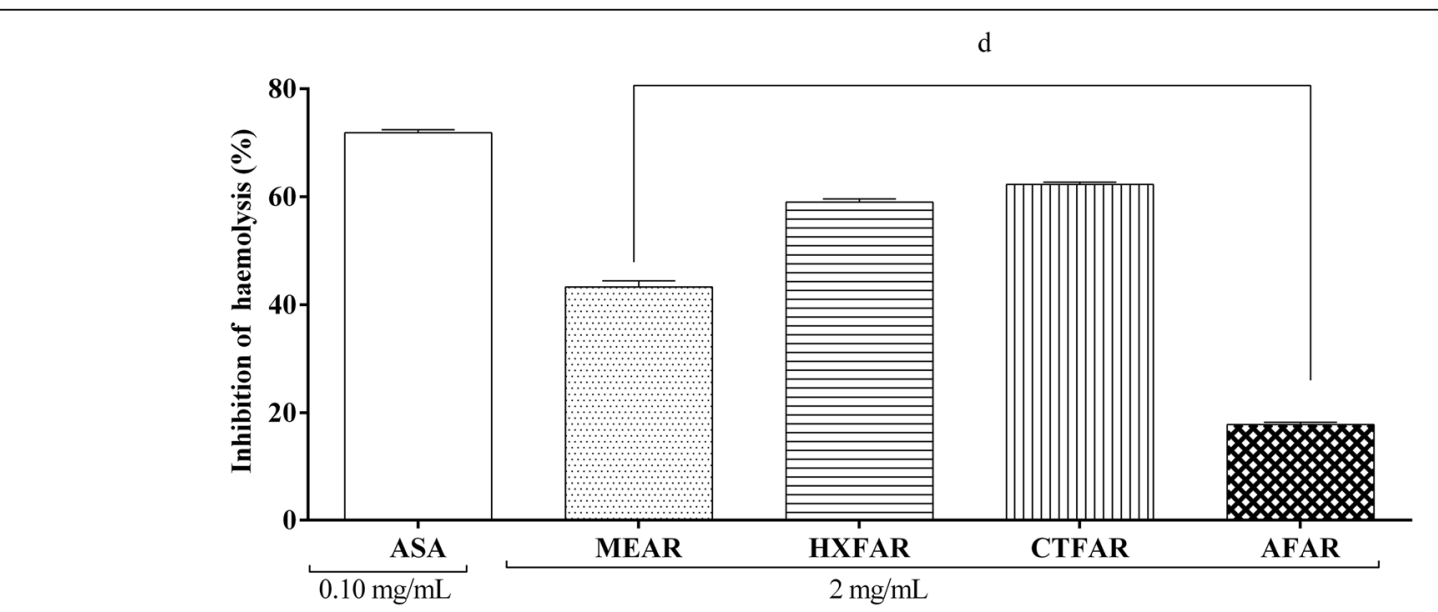

Fig. 1 Effect of different extracts of stem of Albizia richardiana on hypotonic solution-induced haemolysis of erythrocyte membrane. Values are represented in Mean $\pm \operatorname{SEM}(n=3) .{ }^{d} P<0.0001$ considered as statistically significant in comparison to positive control acetylsalicylic acid 


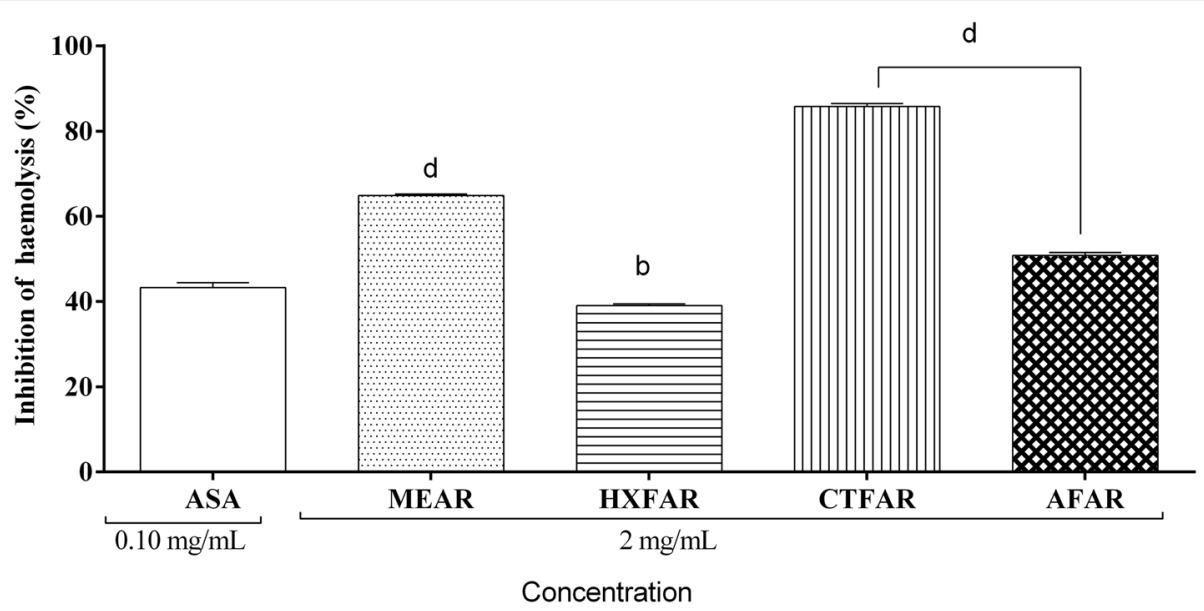

Fig. 2 Effect of different extracts of stem of Albizia richardiana on heat induced haemolysis of erythrocyte membrane. Values are represented in Mean \pm SEM $(n=3) .{ }^{d} P<0.0001$ and ${ }^{b} P<0.01$ considered as statistically significant in comparison to positive control acetylsalicylic acid

\section{Thrombolytic activity}

In this study, the thrombolytic activity, among all extract only MEAR exhibit extremely significant $(P<0.0001)$ clot lysis while all other plant extracts of $A$. richardiana was found to be negligible (Fig. 3). The amounts of thrombolytic activity were present in Methanol soluble fraction (MEAR-16.66\%), chloroform soluble fraction (CFAR-2.15\%), Hexane soluble fraction (HXFAR-3.22\%), carbon tetrachloride soluble fraction (CTFAR-4.68\%) and AFAR have no thrombolytic activity. Therefore, it can be concluded that the extracts of $A$. richardiana showed very poor clot lysis activity compared to standard substance Streptokinase (SK-70.94\%).
In recent years, the formation of a clot in blood has been a serious problem in blood circulation. Blocking off the blood vessel due to the formation of thrombus, which impedes the blood flow. So, the normal oxygen supply and blood flow was deprived. Plasmin is a fibrinolytic drug, blood clot formed by thrombin which lysed by plasmin. This plasmin activated by tPA. The fibrinolytic drug dissolved the thrombin in coronary arteries to reassure the blood flow [36]. In our present study, the clot lysis formation was found to be negligible while in comparison to standard drug streptokinase, whereas only MEAR found to be significant.

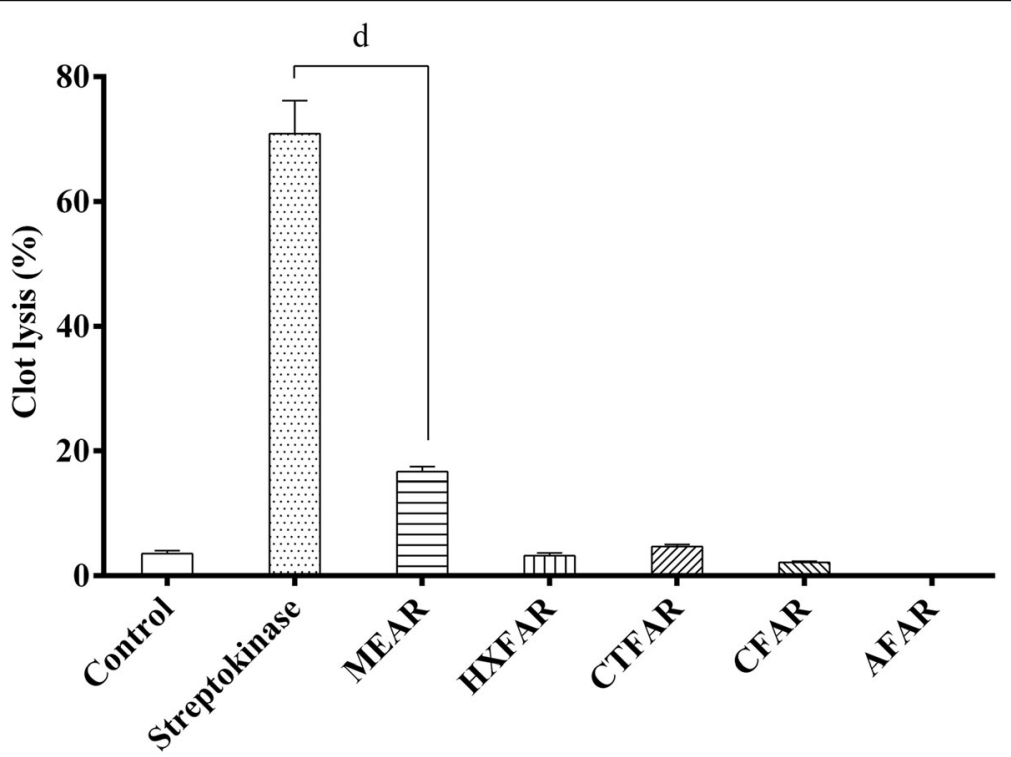

Fig. 3 Thrombolytic activity of different extractives of stem of Albizia richardiana on human blood. Values are represented in Mean \pm SEM $(n=3)$. d $\mathrm{P}<0.0001$ considered as statistically significant in comparison to control group 


\section{Conclusion}

This study suggested that extracts of $A$. richardiana have significant activity in free radical scavenging activity and anti-inflammatory effects. Besides, among the fractions carbon tetrachloride fraction of the stem extract showed promising antimicrobial effect. Notably, among the entire extracts only methanol extract exhibited most significant clot lysis effect while all other plant extracts of $A$. richardiana was found to be negligible. So, this result suggesting $A$. richardiana can be a potential source for biological activity. However, further investigations are required to evaluate the specific compounds form $A$. richardiana stems.

\section{Abbreviations}

MEAR: Methanolic extract of Albizia richardiana; HXFAR: N-hexane fraction of Albizia richardiana; CTFAR: Carbon tetrachloride fraction of Albizia richardiana; CFAR: Chloroform fraction of Albizia richardiana; AQFAR: Aqueous fraction of Albizia richardiana; ROS: Reactive oxygen species; DMSO: Dimethyl sulfoxide; GPB: Gram positive bacteria; GNB: Gram negative bacteria

\section{Acknowledgements}

Authors are thankful to Department of Pharmacy, International Islamic University Chittagong, Chittagong, Bangladesh and Department of Pharmacy, State University of Bangladesh, Dhaka, Bangladesh for their research facilities and support.

\section{Authors' contributions}

MNI, SMT, MMK, MRM, SMR, MAH and CKA together planned and designed the research. SMT arranged the whole facilities for the research and supervised the whole research. MNI conducted the entire laboratory works. $\mathrm{MNI}$ and $\mathrm{AMT}$ imparted in study design and interpreted the results putting efforts on statistical analysis with MNI, HT, AMT, SMR, LA and MAH participated in the manuscript draft and has thoroughly checked and revised the manuscript for necessary changes in format, grammar and English standard. All authors read and agreed on the final version of the manuscript.

\section{Funding}

This work is conducted with the individual funding of all authors

\section{Availability of data and materials}

The datasets used and/or analyzed during the current study are available from the corresponding author on reasonable request.

\section{Ethics approval and consent to participate}

Not applicable.

\section{Consent for publication}

All authors have agreed to publish all materials belongs to this article.

\section{Competing interests}

Authors declared that they have no Competing interests.

\section{Author details}

1Department of Pharmacy, International Islamic University Chittagong, Chittagong-4318, Bangladesh. ${ }^{2}$ Department of Pharmacy, State University of Bangladesh, Dhaka-1205, Bangladesh. 3Dhaka Medical College and Hospital, Dhaka 1000, Bangladesh. ${ }^{4}$ Department of Pharmacy, Forman Christian College (A Chartered University), Lahore, Pakistan. ${ }^{5}$ Drug and Herbal Research Centre, Faculty of Pharmacy, Universiti Kebangsaan Malaysia, 50300 Kuala Lumpur, Malaysia.
Received: 15 November 2019 Accepted: 28 August 2020

Published online: 01 September 2020

\section{References}

1. Sandberg F, Corrigan D. Natural remedies: their origins and uses. CRC Press; 2001.

2. Schulz V, Hänsel R, Tyler VE. Rational phytotherapy: a physician's guide to herbal medicine. Psychology Press; 2001.

3. Bodeker G, Ong CK. WHO global atlas of traditional, complementary and alternative medicine. World Health Organization; 2005.

4. Allan GJ, Porter JM. Tribal delimitation and phylogenetic relationships of Loteae and Coronilleae (Faboideae: Fabaceae) with special reference to Lotus: evidence from nuclear ribosomal ITS sequences. Am J Bot. 2000; 87(12):1871-81.

5. Joycharat $\mathrm{N}$, Thammavong S, Limsuwan S, Homlaead S, Voravuthikunchai $S P$, Yingyongnarongkul B-E, et al. Antibacterial substances from Albizia myriophylla wood against cariogenic Streptococcus mutans. Arch Pharm Res. 2013;36(6):723-30.

6. Xinrong $Y$, Anmin C, Fang S, Bingyi F, Jinlin Q, Yingfu M, Quan L, Yuan G, Shuqian W, Werner $H$, Zhemin G, editors. Encyclopedic reference of traditional Chinese medicine. Springer Science \& Business Media; 2003.

7. Rahman M, Jahan Shetu H, Sukul A, Rahman I. Phytochemical and biological evaluation of albizia richardiana benth, Fabaceae family. World J Pharm Res. 2015:4990:168-76

8. Park CH, Yeo HJ, Kim NS, Eun PY, Kim S-J, Arasu MV, et al. Metabolic profiling of pale green and purple kohlrabi (Brassica oleracea var. gongylodes). Appl Biol Chem. 2017;60(3):249-57.

9. Higdon JV, Delage B, Williams DE, Dashwood RH. Cruciferous vegetables and human cancer risk: epidemiologic evidence and mechanistic basis. Pharmacol Res. 2007;55(3):224-36.

10. Douglas CJ. Phenylpropanoid metabolism and lignin biosynthesis: from weeds to trees. Trends Plant Sci. 1996;1(6):171-8.

11. Jahangir M, Kim HK, Choi YH, Verpoorte R. Health-affecting compounds in Brassicaceae. Compr Rev Food Sci Food Saf. 2009:8(2):31-43.

12. Thomas C. Oxygen radicals and the disease process. CRC Press; 1998.

13. Kaushik A, Jijta C, Kaushik JJ, Zeray R, Ambesajir A, Beyene L. FRAP (Ferric reducing ability of plasma) assay and effect of Diplazium esculentum (Retz) Sw. (a green vegetable of North India) on central nervous system; 2012.

14. Dudonne S, Vitrac X, Coutiere P, Woillez M, Merillon JM. Comparative study of antioxidant properties and total phenolic content of 30 plant extracts of industrial interest using DPPH, ABTS, FRAP, SOD, and ORAC assays. J Agric Food Chem. 2009;57(5):1768-74.

15. Antolovich M, Prenzler PD, Patsalides E, McDonald S, Robards K. Methods for testing antioxidant activity. Analyst. 2002;127(1):183-98.

16. Mates JM, Perez-Gomez C, Nunez de Castro I. Antioxidant enzymes and human diseases. Clin Biochem. 1999:32(8):595-603.

17. Gutteridge JM. Biological origin of free radicals, and mechanisms of antioxidant protection. Chem Biol Interact. 1994:91(2-3):133-40.

18. García-Andrade M, González-Laredo R, Rocha-Guzmán N, Gallegos-Infante J, Rosales-Castro M, Medina-Torres L. Mesquite leaves (Prosopis laevigata), a natural resource with antioxidant capacity and cardioprotection potential. Ind Crop Prod. 2013:44:336-42.

19. VanWagenen BC, Larsen R, Cardellina JH, Randazzo D, Lidert ZC, Swithenbank C. Ulosantoin, a potent insecticide from the sponge Ulosa ruetzleri. J Org Chem. 1993;58(2):335-7.

20. Brand-Williams W, Cuvelier ME, Berset C. Use of a free radical method to evaluate antioxidant activity. LWT Food Sci Technol. 1995;28(1):25-30.

21. Škerget $M$, Kotnik $P$, Hadolin $M$, Hraš $A R$, Simonič $M$, Knez Ž. Phenols, proanthocyanidins, flavones and flavonols in some plant materials and their antioxidant activities. Food Chem. 2005;89(2):191-8.

22. Meyer B, Ferrigni N, Putnam J, Jacobsen L, Nichols DJ, McLaughlin JL. Brine shrimp: a convenient general bioassay for active plant constituents. Planta Med. 1982:45(05):31-4.

23. Barry AL. The antimicrobic susceptibility test: principles and practices. Lippincott Williams \& Wilkins; 1976.

24. Bauer AW, Kirby WM, Sherris JC, Turck M. Antibiotic susceptibility testing by a standardized single disk method. Am J Clin Pathol. 1966;45(4):493-6.

25. Shinde U, Phadke A, Nair A, Mungantiwar A, Dikshit V, Saraf M. Membrane stabilizing activity - a possible mechanism of action for the antiinflammatory activity of Cedrus deodara wood oil. Fitoterapia. 1999;70(3): $251-7$. 
26. Rock $\mathrm{CL}$, Jacob RA, Bowen PE. Update on the biological characteristics of the antioxidant micronutrients: vitamin $\mathrm{C}$, vitamin $\mathrm{E}$, and the carotenoids. Am Diet Assoc. 1996;96(7):693-702 quiz 3-4.

27. McCord JM. The evolution of free radicals and oxidative stress. Am J Med. 2000;108(8):652-9.

28. Rao AL, Bharani M, Pallavi V. Role of antioxidants and free radicals in health and disease. Adv Pharmacol Toxicol. 2006;7(1):29-38.

29. Blokhina O, Virolainen E, Fagerstedt KV. Antioxidants, oxidative damage and oxygen deprivation stress: a review. Ann Bot. 2003;91 Spec No:179-94.

30. Pandey KB, Rizvi SI. Plant polyphenols as dietary antioxidants in human health and disease. Oxidative Med Cell Longev. 2009;2(5):270-8.

31. Santos-Sánchez NF, Salas-Coronado R, Villanueva-Cañongo C, HernándezCarlos B. Antioxidant compounds and their antioxidant mechanism. InAntioxidants 2019 Mar 22. IntechOpen.

32. Nguta J, Mbaria J, Gakuya D, Gathumbi P, Kabasa J, Kiama S. Biological screening of Kenyan medicinal plants using Artemia salina (Artemiidae). Pharmacologyonline. 2011;2:458-78

33. Omale J, Okafor PN. Comparative antioxidant capacity, membrane stabilization, polyphenol composition and cytotoxicity of the leaf and stem of Cissus multistriata. Afr J Biotechnol. 2008;7(17).

34. Oyedapo O. Biological activity of Plyllanthus amarus extracts on pragrowDawley rats. Nig J Biochem Mol Biol. 2001;26:202-26.

35. El-Shabrawy O, El-Gindi O, Melek F, Abdel-Khalik S, Haggag M. Biological properties of saponin mixtures of Fagonia cretica and Fagonia mollis. Fitoterapia. 1997;68(3):219-22.

36. Laurence D. Ethics and law in clinical pharmacology. Br J Clin Pharmacol. 1989;27(6):715

\section{Publisher's Note}

Springer Nature remains neutral with regard to jurisdictional claims in published maps and institutional affiliations.

\section{Submit your manuscript to a SpringerOpen ${ }^{\circ}$ journal and benefit from:}

- Convenient online submission

- Rigorous peer review

- Open access: articles freely available online

- High visibility within the field

- Retaining the copyright to your article 